\title{
Mdm2 links genotoxic stress and metabolism to $\mathrm{p53}$
}

\author{
Zhongfeng Wang, Baojie $\mathrm{Li}^{\bowtie}$
}

Bio-X Center, Key Laboratory for the Genetics of Developmental and Neuropsychiatric Disorders, Ministry of Education, Shanghai Jiao Tong University, Shanghai 200240, China

$\bowtie$ Correspondence: libj.bio@gmail.com

Received November 17, 2010 Accepted November 30, 2010

\begin{abstract}
Mouse double minute 2 (Mdm2) gene was isolated from a cDNA library derived from transformed mouse 3T3 cells, and was classified as an oncogene as it confers 3 T 3 and Rat2 cells tumorigenicity when overexpressed. It encodes a nucleocytoplasmic shuttling ubiquitin E3 ligase, with its main target being tumor suppressor p53, which is mutated in more than $50 \%$ of human primary tumors. Mdm2's oncogenic activity is mainly mediated by p53, which is activated by various stresses, especially genotoxic stress, via Atm (ataxia telangiectasia mutated) and Atr (Atm and Rad3-related). Activated p53 inhibits cell proliferation, induces apoptosis or senescence, and maintains genome integrity. Mdm2 is also a target gene of p53 transcription factor. Thus, Mdm2 and p53 form a feedback regulatory loop. External and internal cues, through multiple signaling pathways, can act on Mdm2 to regulate p53 levels and cell proliferation, death, and senescence. This review will focus on how Mdm2 is regulated under genotoxic stress, and by the Akt1mTOR-S6K1 pathway that is activated by insulin, growth factors, amino acids, or energy status.
\end{abstract}

KEYWORDS mouse double minute 2 (Mdm2), p53, signal transduction, tumorigenesis

\section{MDM2 AND P53, AN INSEPARABLE COUPLE}

Mdm2 consists of 489 amino acids while its human counterpart Hdm2 consists of 491 amino acids. This protein contains several conserved structural domains including an $\mathrm{N}$-terminal p53 interaction domain, a central acidic domain (residues 230-300) that possesses multiple phosphorylation sites and nuclear export and import signals, a Zinc finger domain, a
C-terminal RING domain (residues 430-480) that contains a Cys3-His2-Cys3 motif which confers E3 ubiquitin ligase activity. The RING domain of Mdm2 can also bind to RNA and contains a nucleolar localization sequence. As an E3 ubiquitin ligase, Mdm2 has many substrates, including p53, forkhead box O (FOXO) (Fu et al., 2009), dihydrofolate reductase (Maguire et al., 2008), interferon regulatory factor 2 (IRF-2) (Pettersson et al., 2009), runt-related transcription factor (RUNX3) (Chi et al., 2009), activating transcription factor 3 (ATF3) (Mo et al., 2010), HIV-1 viral infectivity factor (HIV-1 vif) (Izumi et al., 2009), and Slug (Kim et al., 2010), with p53 being the most extensively studied substrate.

p53 is a prototypical tumor suppressor that is mutated in more than $50 \%$ of primary human tumors. As a master transcription regulator, p53 can either activate or repress transcription, depending on the target genes. For transactivation, p53 usually needs to bind to the promoter of target genes as a tetramer, with a consensus binding sequence $5^{\prime}$ RRRCWWGYYY-N (0-13)-RRRCWWGYYY-3' (R: A/G, W: $A / T, Y: T / C)$. The best studied p53 target genes include p21, Mdm2, Puma and Bax. Through upregulation of these genes, p53 exhibits an anti-proliferation activity by inducing cell cycle arrest, apoptosis, and/or senescence.

p53 activity is tightly controlled at multiple levels including transcription, translation, and protein stability, with protein stabilization as a major mechanism. The main stimuli of p53 expression include DNA damage (caused by UV, ionizing radiation (IR), or genotoxic drugs), oxidative stress, osmotic shock, ribonucleotide depletion, and deregulated oncogene activation. Genotoxic stress activates PI3 kinase-like-kinases including DNA-PKc, Atm, and Atr at the DNA break sites, which in turn phosphorylate p53, Mdm2 and other proteins, leading to p53 stabilization/activation (Zhou and Elledge, 2000; Kastan and Bartek, 2004; Li, 2005). In addition to tumor suppression, recent studies also suggest that p53 plays a role 
in aging. Overactivation of p53 leads to premature aging in mouse models (Tyner et al., 2002).

p53 is expressed at very low levels in normal cells. This is most likely attributable to the feedback regulatory loop between Mdm2 and p53. Mdm2 ubiquitinates p53 in the nucleus, leading to p53 nuclear export and proteosomemediated degradation. On the other hand, Mdm2 is a direct target gene of p53 (Barak et al., 1994). Therefore elevation of p53 upregulates Mdm2, which in turn downregulates p53 (Iwakuma and Lozano, 2003). The significance of this regulatory loop is manifested by the genetic studies of $\mathrm{Mdm}^{-{ }^{-}}$and $\mathrm{Mdm}^{-{ }^{-}} \mathrm{p} 53^{--}$mice. Knockout mice of Mdm2 show embryonic lethality, accompanied by an elevation of p53. Deletion of p53 in $\mathrm{Mdm}^{-/-}$mice rescued the embryonic lethality phenotype, suggesting that p53 mediates the effects of Mdm2 deficiency on mouse development and survival (de Oca Luna et al., 1995; Jones et al., 1995). In addition, polymorphism of Mdm2 promoter alters the tumorigenesis processes, which is also mediated by the change in p53 activity (Bond et al., 2004).

Mdm2 negatively regulates the stability of $p 53$. Ubiquitination by $\mathrm{Mdm} 2$ is necessary for p53 nuclear export and degradation. The ubiquitination is dependent on the association between these two proteins (Fuchs et al., 1998). Mdm2 binding-deficient p53 mutant could not be ubiquitinated by Mdm2 (Inoue et al., 2001). For both Mdm2 and p53, the binding sites were originally mapped to their $\mathrm{N}$-terminal domains (Chen et al., 1993). It was later shown that the carboxyl terminal domain of p53 alone could also mediate its interaction with Mdm2 (Poyurovsky et al., 2010). The RING domain is essential for Mdm2 E3 ligase activity (Fang et al., 2000; Honda and Yasuda, 2000; Poyurovsky et al., 2007). In addition, the RING domain might be involved in substrate recognition as Mdm2 with its RING domain replaced with that of Praja1 could ubiquitinate Mdm2 but not p53 (Fang et al., 2000), and sumoylation of Mdm2 at Lys446, a residue locating within the RING finger domain enhances its ubiquitin ligase activity toward p53 (Buschmann et al., 2000). Moreover, ubiquitination depends on p53 oligomerization as Mdm2 could not target oligomerization-deficient p53 for ubiquitination (Maki, 1999; Hjerpe et al., 2010). Ubiquitinated p53 exists in two forms, monoubiquitination, which might elicit nuclear export of p53, and polyubiquitination, which promotes proteasomal degradation of p53 (Li et al., 2003). RFWD3 (ring finger and WD repeat domain 3 ), an Mdm2 stabilizer, is able to enhance Mdm2-mediated p53 mono-ubiquitination in response to IR (Fu et al., 2010), yet, it suppresses polyubiquitination of $p 53$, thus stabilizing $p 53$. In addition, it is reported that phosphorylation of p53 at Ser46 renders p53 resistant to Mdm2-meidiated ubiquitination (Di Stefano et al., 2004).

Besides mediating p53 turnover, Mdm2 could also affect the activity of $p 53$ through various mechanisms. First, Mdm2 binds to the transactivation domain of p53 and inhibits its transcriptional activity possibly through blocking its access to target genes (Momand et al., 1992; Kussie et al., 1996). Secondly, Mdm2 inhibits the translation of p53 by targeting ribosomal protein L26 (RPL26) that would otherwise enhance p53 mRNA translation (Ofir-Rosenfeld et al., 2008), although studies from Candeias et al. reported a seemingly contrary result (Candeias et al., 2008; Naski et al., 2009). They showed that p53mRNA-Mdm2 interaction augments p53 mRNA translation and decreases Mdm2 E3 ligase activity. Nevertheless, these findings further suggest a close relationship between Mdm2 and p53 (Fig. 1).

\section{THE P53-DEPENDENT FUNCTIONS OF MDM2}

Tumor suppressors often control cell proliferation and death (Allred et al., 1993). As a negative regulator of tumor suppressor p53, Mdm2 appears to promote cell proliferation and inhibit apoptosis. In most cases, the effects of Mdm2

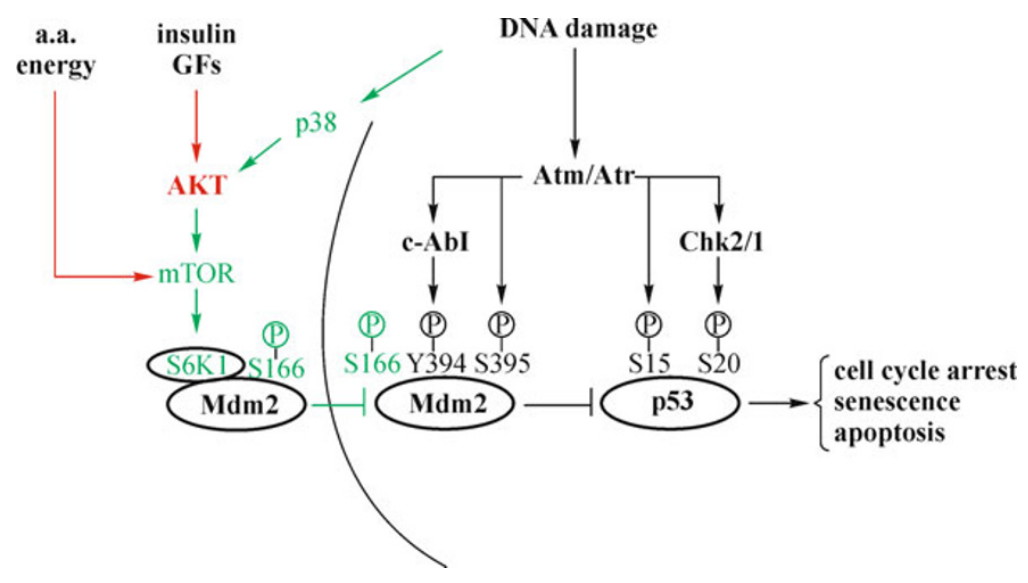

Figure 1. Mdm2 phosphorylation pathways. In response to DNA damage, insulin, growth factors, amino acids, and energy status, Mdm2 could be phosphorylated on various sites through different pathways, including p38/AKT/mTOR/S6K1 pathway and Atm/c-Abl pathway. Through targeting p53, Mdm2 regulates cell proliferation, senescence, and apoptosis. a.a.: amino acids; GFs: growth factors. 
require the presence of p53. Ciardiello's group observed that antisense oligonucleotides of Mdm2 could enhance the growth-inhibitory effect of certain cytotoxic drugs in human colon cancer with functional p53 (Tortora et al., 2000). Shangary et al. designed a small-molecule inhibitor to disrupt Mdm2-p53 interaction, which inhibits cell proliferation (Shangary et al., 2008). In normal cells, e.g., human fibroblasts, the antibodies that can block Mdm2-p53 interaction augment p53-mediated suppression of cell proliferation (Blaydes and Wynford-Thomas, 1998). These findings, together with the pivotal role of Mdm2 in maintaining p53 at critical physiologic levels, suggest that Mdm2 is essential for the proliferation of normal and cancer cells.

In addition, by negatively regulating p53, Mdm2 could inhibit apoptosis and enhance cell survival. Overexpression of Mdm2 protects human glioblastoma U87-MG cells from chemotherapeutic drug cisplatin-induced apoptosis, which could otherwise be enhanced by treatment with antisense oligonucleotide targeting Mdm2 mRNA (Kondo et al., 1995). During p53-mediated apoptosis, Mdm2 is cleaved by interleukin $1 \beta$-converting enzyme-like proteases (caspases) with its $\mathrm{COOH}$-terminal RING finger removed (Chen et al., 1997). The resultant Mdm2 could still bind to p53 and inhibit p53meidated transcription (Chen et al., 1997), but failed to destabilize p53 (Pochampally et al., 1999).

\section{THE P53-INDEPENDENT FUNCTIONS OF MDM2}

However, some others reported that Mdm2 could also regulate cell proliferation in the absence of $p 53$. One example is cell cycle arrest caused by Rb. p107 is a member of Rb tumor suppressor family, and it could induce $G_{1}$ cell-cycle arrest. Mdm2 reverses this effect in the absence of p53 (Dubs-Poterszman et al., 1995). Transforming growth factor- $\beta$ (TGF- $\beta$ ) treatment causes growth arrest by promoting $\mathrm{Rb}$ dephosphorylation and preventing E2F1 activation (Sun et al., 1998). Under this setting, Mdm2 could reverse the effect of TGF- $\beta$ on cell proliferation in the absence of p53. The underlying mechanism is that $\mathrm{Mdm} 2$ can target $\mathrm{Rb}$ for degradation or phosphorylation. What's more, Argentini et al. reported that mutant Mdm2 that is defective in mediating p53 ubiquitination/degradation could still induce cell proliferation (Argentini et al., 2000). Taken together, these observations suggest that Mdm2 could also promote cell proliferation through pathways not involving p53.

Additionally, Mdm2 could regulate apoptosis without directly acting on p53. It has been reported that Mdm2 could induce degradation of the proapoptotic activator homeodomain-interacting protein kinase 2 (HIPK2), which is responsible for p53 phosphorylation on Ser46. Hypophosphorylation on Ser46 compromises p53 activation and subsequently p53-mediated apoptosis. Furthermore, inhibition of Mdm2 could also induce apoptosis in some cell lines lacking functional p53, including p53 null cell lines such as human colon cancer cell line Caco2 and p53 mutant cell line HuCCT1 (Ray et al., 2010; Zheng et al., 2010). Under these conditions, accumulation of p73 and the concomitant induction of Puma might account for apoptosis induction.

\section{REGULATION OF MDM2 AT THE TRANSCRIPTIONAL LEVELS}

The Mdm2 gene has 12 exons and two distinct promoters, designated $\mathrm{P} 1$ and $\mathrm{P} 2$, which control the basal expression and inducible expression of Mdm2 respectively (Barak et al., 1994; Manfredi, 2010). Within the P2 promoter, there are two p53 binding sites and binding sites for other transcription factors such as adaptor protein 1 (AP-1) and Ets (Ries et al., 2000; Truong et al., 2005; Hollenhorst et al., 2007; Pikkarainen et al., 2009). p53 can transactivate P2 promoter and promote Mdm2 expression (Juven et al., 1993; Wu et al., 1993; Barak et al., 1994; Moll and Petrenko, 2003). Then, Mdm2 forms a complex with p53 and inhibits its transcriptional activity on Mdm2 promoter (Wu et al., 1993). This regulation appears to require the transformation/transcription domain-associated protein (TRRAP) acetyltransferase complexes (Ard et al., 2002).

Transcription of Mdm2 can be regulated in a p53independent manner as well. Transcription factor nuclear factor K-B (NF-KB) was demonstrated to bind to P1 promoter of $M d m 2$ and enhance its expression (Busuttil et al., 2010). Ras/Raf binds to AP-1 response element (Ries et al., 2000; Halaschek-Wiener et al., 2004), while Ets transcription factors Fli-1 (Truong et al., 2005) and Elf4/Mef (Sashida et al., 2009) bind to $M d m 2 \mathrm{P} 2$ promoter at the Ets responsive element, to elevate the expression of Mdm2. In neuroblastoma, v-myc myelocytomatosis viral related oncoprotein (MYCN) can directly bind to the consensus E-box of the human $\mathrm{Hdm} 2$ P2 promoter and upregulate the expression of Hdm2 (Slack et al., 2005).

Through p53 and other transcription factors, a number of cellular or extracellular signals could influence the expression of Mdm2. In a recent report, expression of human $\mathrm{Hdm} 2$ was observed to be induced by TGF- $\beta 1$-activated SMAD3 and SMAD4 (Smad3/4) transcription factors which could specifically bind to the P2 promoter region of $\mathrm{Hdm} 2$ (Araki et al., 2010). Through an intron sequence, thyroid hormone can regulate Mdm2 expression in a p53-independent manner (Qi et al., 1999). The correlation between estrogen status and Mdm2 mRNA levels was also observed in human breast carcinoma (Sheikh et al., 1993). Sheikh et al. showed that the estrogen receptor (ER)-positive cells express much higher levels of Mdm2 than ER-negative cells by a mechanism independent of ER-function but involving the P2 promoter (Phelps et al., 2003). Oxidative stress induces the transcription of Mdm2 possibly by promoting AP-1 expression (Pikkarainen et al., 2009). Moreover, potent anti-tumor agent gambogic acid (GA) could downregulate the Mdm2 
mRNA levels (Rong et al., 2009). Both the P1 and P2 promoters of $M d m 2$ are involved in the response to GA, although the mechanism behind this regulation remains elusive. Finally, a microRNA termed miR-221 is recently shown to be able to negatively regulate Mdm2 at RNA level through targeting its $3^{\prime}$-untranslated region (3'-UTR) (Kim et al., 2010).

\section{REGULATION OF MDM2 STABILITY}

As an E3-ligase, Mdm2 targets itself for ubiquitin-dependent proteasome-mediated degradation (Chang et al., 1998). The RING finger domain is necessary for Mdm2 self-ubiquitination (Honda and Yasuda, 2000). On the other hand, the ubiquitin moiety can be removed by deubiquitinase hepes simplex virus associated ubiquitin-specific protease (HAUSP) and ubiquitin-specific protease 2a (USP2a), which facilitate Mdm2 stabilization ( $\mathrm{Li}$ et al., 2004; Stevenson et al., 2007). In addition to ubiquitination, Mdm2 can also be sumoylated at Lys 446 by Ubc 9 , which has a strong sequence homology to ubiquitin carrier proteins (E2s) and binds to the aa 40-59 of Mdm2 (Buschmann et al., 2001). Lys446 is required for Mdm2 ubiquitin ligase activity as well (Buschmann et al., 2000). Sumoylation stabilizes $\mathrm{Mdm} 2$ by inhibiting its selfubiquitination, but destabilizes p53 due to enhanced Mdm2 ubiquitin ligase activity toward p53. Reversely, desumoylation carried out by SUMO-specific protease, SUSP4, results in promotion of Mdm2 self-ubiquitination and p53 stabilization (Lee et al., 2006).

Apart from that, a number of proteins have been identified as inhibitors of Mdm2 self-ubiquitination, including $M d m x$, MTBP, PKB, HAUSP, USP2a, CSN5, and ARF (Stad et al., 2001; Feng et al., 2004; Li et al., 2004; Brady et al., 2005; Zhang et al., 2008). Mdmx, a structural homolog of Mdm2, stabilizes Mdm2 through heterodimerization via their RING fingers (Stad et al., 2001). Death-domain-associated protein (DAXX) stabilizes Mdm2 via the stabilizing effect of HAUSP on Mdm2 (Tang et al., 2006). The 5th subunit of COP9 signalosome (CSN5, also known as Jab1 or COPS5) was also reported to reduce $\mathrm{Mdm} 2$ self-ubiquitination by an unidentified mechanism (Zhang et al., 2008). RFWD3, an E3 ubiquitin ligase, is recently identified as a stabilizer of Mdm2 (Fu et al., 2010). Mdm2 could be degraded more rapidly in vivo once RFWD3 is knocked down. However, the mechanism is not yet identified. More importantly, ARF can bind Mdm2 and induce re-localization of Tyr276phosphorylated Mdm2 to the nucleolus and neutralizes its activity toward p53 (Dias et al., 2006). Just like ARF, some ribosomal proteins could also inhibit Mdm2 through binding to its acidic domain (reviewed in Manfredi, 2010).

Different from the proteins aforementioned, Rasassociation domain family protein isoform 1A (RASSF1A),

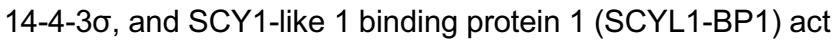
as destabilizers of Mdm2 (Yang et al., 2007; Song et al., 2008;
Yan et al., 2010). RASSF1A, a tumor suppressor, disrupts the association among Mdm2, DAXX, and HAUSP in the nucleus, resulting in an enhancement of self-ubiquitin ligase activity of Mdm2 (Song et al., 2008). 14-4-3 $\sigma$ and SCYL1-BP1 were both reported to bind to Mdm2 and to promote its selfubiquitination and turnover by poorly understood mechanisms (Yang et al., 2007; Yan et al., 2010).

While inhibition of Mdm2 self-ubiquitination usually stabilizes Mdm2 and promotes p53 ubiquitination and degradation (Buschmann et al., 2000; Brady et al., 2005; Tang et al., 2006), there are several exceptions. For example, Mdmx stabilizes both Mdm2 and p53 by different mechanisms (Stad et al., 2001). Moreover, upon the activation of G-proteincoupled receptors (GPCRs), Mdm2 is recruited to GPCRs at plasma membrane through binding to $\beta$-arrestin, an important adapter and scaffold in signaling of GPCRs. As a result, both p53 ubiquitination and Mdm2 self-ubiquitination are reduced (Wang et al., 2003).

\section{REGULATION OF MDM2 BY AKT1-MEDIATED PHOSPHORYLATION}

Modification by phosphorylation is a major means to regulate Mdm2 function. The level of Mdm2 phosphorylation is usually reverse-correlated with its activity toward p53 (Blattner et al., 2002). Phosphorylation may regulate $\mathrm{Mdm} 2$ selfubiquitination, nucleocytoplasmic shuttling, Mdm2-p53 interaction, etc. Multiple phosphorylation sites have been identified on Mdm2 (reviewed in Waning et al., 2010). Both mitogenic signals and certain cellular stresses (e.g., genotoxic stress) could induce Mdm2 phosphorylation through various pathways (Meek and Hupp, 2010). In response to mitogenic signals, Mdm2 could be phosphorylated on Serines $157,166,186$ and 188. Given the fact that these residues are located near the nuclear localization signal (NLS) and nuclear export signal (NES) of Mdm2, it is not surprising that phosphorylation on these sites influences the nuclear translocation of Mdm2 (Mayo and Donner, 2001). Ser166 and Ser186 could be phosphorylated by Akt (Mayo and Donner, 2001; Zhou and Hung, 2002), Pim protein kinases (Pim-1, -2 and -3) in vivo (Hogan et al., 2008; Wood et al., 2009), and by ribosomal S6 kinase (RSK) in vitro. Ser188 could be phosphorylated by both Akt and Pim (Feng et al., 2004; Milne et al., 2004; Wood et al., 2009), while Ser157 is a target of MK2 (MAPKAPK-2) (Meek and Hupp, 2010).

The association of Mdm2 and Akt was observed in MCF-7 cells, HER-2 3T3 and DN-Akt 3T3 cells (Mayo and Donner, 2001; Zhou et al., 2001). Once Akt is activated by insulin-like growth factor-1 (IGF-1) or insulin in a PI3-kinase-dependent manner, it phosphorylates Mdm2 on Ser166 and Ser186 (Mayo and Donner, 2001). In vitro kinase assay further confirmed that Mdm2 is a bona fide substrate of Akt (Zhou et al., 2001), and in the experiments conducted by two other groups, Ser188 was found to be a target of Akt as well (Feng 
et al., 2004; Milne et al., 2004). Akt-mediated phosphorylation promotes Mdm2 activation, stabilization, and redistribution to the nucleus, where it destabilizes p53 through ubiquitination (Mayo and Donner, 2001; Zhou et al., 2001; Feng et al., 2004). This has been postulated to be a mechanism by which activated Akt promotes tumorigenesis.

Just like Akt, Pim kinases could interact with Mdm2 in vivo and phosphorylate Mdm2 at Ser166 in vitro (Hogan et al., 2008). It should be noted that, although Pim-mediated phosphorylation elevates Mdm2 protein levels, it does not enhance p53 degradation, which is possibly due to the enhanced interaction between Mdm2 and its inhibitor ARF. Thus, Akt and Pim could phosphorylate Mdm2 on the same sites but get different outcomes. In addition, it has been reported that Pim-phosphorylated Mdm2 binds to 14-3-3, while Mdm2 phosphorylated by PKB/Akt pathway does not (Wood et al., 2009). Phosphorylation of Ser186 by Pim prevents Ser188 from being further phosphorylated by PKB/ Akt pathway. 14-3-3 and ARF negatively regulate the activity of Mdm2, and this might explain why Pim-phosphorylated Mdm2 would not cause downregulation of p53 (Yang et al., 2007).

\section{REGULATION OF MDM2 BY ATM-MEDIATED PHOSPHORYLATION UNDER GENOTOXIC STRESS}

DNA damage is caused by external factors such as UV light and IR, or internal factors such as reactive oxygen species, which leads to activation of Atm (ataxia telangiectasia mutated) and Atr (Atm and Rad3-related), members of the phosphatidyl inositol 3-kinase related kinase (PIKK) family. Atm could phosphorylate Mdm2 directly or through other kinases. Khosravi and his colleagues found that Mdm2 could be phosphorylated in an Atm-dependent manner in vivo, and that Atm could phosphorylate Mdm2 in vitro (Khosravi et al., 1999). Other groups also confirmed Mdm2 as a direct substrate of Atm (Maya et al., 2001; Cheng et al., 2009). Atm could directly phosphorylate Mdm2 on Ser395, 386 and 429 in vivo, residues adjacent to the RING domain. Phosphorylation of these residues disrupts the formation of RING oligomerization, thus preventing p53 polyubiquitination and leading to p53 stabilization (Cheng et al., 2009; Cheng and Chen, 2010). Atm-mediated Mdm2 phosphorylation destabilizes Mdm2 by impairing its binding to HAUSP (Meulmeester et al., 2005). In addition, phosphorylation of Mdm2 at Ser395 by Atm could be reversed by p53-induced phosphatase 1 (Wip1) (Lu et al., 2007; Lu et al., 2008). Through dephosphorylation, Wip1 stabilizes Mdm2 and enhances its binding toward p53 (Lu et al., 2007). Consequently, dephosphorylation of Mdm2 promotes proteasomemediated degradation of $\mathrm{p} 53$. Additionally, Atm could phosphorylate c-Abl (Abelson tyrosine kinase), which interacts with Mdm2 in vivo and in vitro, and subsequently phosphorylates Mdm2 on Tyr394 and 276 (Goldberg et al., 2002; Dias et al., 2006), which would in turn regulate the interaction of Mdm2 and ARF and facilitate p53 stabilization. Another PIKK family member Atr, which is activated by UV or single-stranded DNA (ssDNA), could also phosphorylate Mdm2, mainly at Ser407 (Shinozaki et al., 2003), yet its significance is less clear.

\section{REGULATION OF MDM2 BY S6K1-MEDIATED PHOSPHORYLATION, A CONNECTION TO CELL METABOLISM}

Besides Atm and Atr, Lai et al. recently found that under genotoxic stress, S6K1 can phosphorylate Mdm2 on Ser163 (Lai et al., 2010). DNA damage transiently activates mTORS6K1 in the cytoplasm, which requires p38 MAPK (mitogenactivated protein kinases) but not Atm/Atr. The activated S6K1, in a T389 phosphorylation dependent manner, forms a tighter complex with Mdm2, phosphorylates Mdm2 at S163 in the cytoplasm, and inhibits Mdm2-mediated p53 ubiquitination, allowing Mdm2 cytoplasmic retention and p53 stabilization. Deactivation of mTOR-S6K1 signaling leads to Mdm2 nuclear translocation, which is facilitated by $\mathrm{S} 163$ phosphorylation, a reduction in p53 induction, and an alteration in p53dependent cell death. These results support a model in which S6K1 regulates $\mathrm{p} 53$ induction in DNA damage response by interacting with and phosphorylating Mdm2. S6K1-Mdm2 interaction presents a route for cells to incorporate the metabolic/energy cues into DNA damage response and links the aging-controlling Mdm2-p53 and mTOR-S6K pathways (Fig. 1).

Lai's study thus reveals another genotoxic stressresponsive pathway, p38-Akt-mTOR-S6K1-Mdm2, which helps to regulate p53 stability. This pathway can also sense the cells' nutrient and energy status and transmits signals to fine-tune cells' response to DNA damage. The interaction between S6K1 and Mdm2 also links two of the prominent pathways that control aging at the cell and organism levels, the mTOR-S6K pathway and the Mdm2-p53 pathway. Further investigation will be needed to determine whether p53 participates in mTOR-S6K1 mediated aging process. These findings might be of help in developing strategies to retain Mdm2 in the cytoplasm to facilitate p53-based cancer therapy.

\section{MDM2 BASED CANCER THERAPY}

Mdm2 acts as an oncoprotein mainly by negatively regulating tumor suppressor p53. Targeting Mdm2 provides a potential strategy for treatment of caner patients with wild-type p53. Inhibition of Mdm2 could be achieved by introduction of antisense oligonucleotides, expressing its antagonists, or treatment with its inhibitors. Antisense therapy has been shown to enhance apoptosis induced by chemotherapy 
reagents (Sato et al., 2000) or irradiation (Grünbaum et al., 2001). In addition, more efforts have been made to search for drugs that inhibit Mdm2 activity.

Aminoflavone (AF, NSC 686, 288) is a potent anti-cancer drug that causes cell cycle arrest by phosphorylating and activating p53 (Meng et al., 2005). AF also inhibits Mdm2 phosphorylation at Ser166 and promotes its polyubiquitination, leading to Mdm2 degradation. So, in response to increasing doses of AF, Mdm2 protein first accumulates and then decreases. The elevated Mdm2 protein level might induce cell cycle arrest, while decrease of Mdm2 would switch cell cycle arrest to apoptosis.

A class of small molecule Mdm2 inhibitors (Mls) were recently discovered to bind to Mdm2, disrupt Mdm2-p53 binding, and reactivate p53 (Ding et al., 2006). Among the inhibitors, MI-63 has the strongest affinity for Mdm2 (Canner et al., 2009). Ml-63 was found to induce apoptosis accompanied by an increased expression of p53, p21 and Bax in Rhabdomyosarcoma (RMS) expressing wild-type p53 but not in cells expressing mutant p53. The p53-dependence was also observed in acute myeloid leukemia (AML) cells (Samudio et al., 2010). Similar to MI-63, Ml-43 induces the accumulation of p53 and activates its transcriptional activity, leading to cell cycle arrest and apoptosis. MI- 43 could also sensitize chemo-resistant A549 cells to etoposide-induced apoptosis when applied in combination with etoposide.

Nutlins are another class of highly potent and specific small-molecule antagonists of Mdm2 (Vassilev et al., 2004). They occupy the p53 binding pocket in Mdm2, resulting in impaired Mdm2-p53 interaction and the release of functional p53. Nutlin-3 induces cellular senescence in a p53dependent manner (Efeyan et al., 2007). Nutlin-3 could only induce apoptosis in AML cells expressing wild-type p53 (Kojima et al., 2005). The same effect could be observed in pediatric acute lymphoblastic leukemia (ALL) cells (Gu et al., 2008b). Nutlin-3 could also induce apoptosis in p53-deficient tumor cells, possibly by disrupting the interaction of Mdm2 and p73, and activated p73 would induce PUMA expression and apoptosis (Ray et al., 2010).

$\mathrm{GA}$, an anticancer agent derived from gamboges, has been proved to regulate $\mathrm{Mdm} 2$ at both transcriptional and posttranslational levels independently of p53 (Gu et al., 2008a). Via the two promoters of Mdm2, GA downregulates Mdm2 at transcriptional level; through the ubiquitinproteosome pathway, GA inhibits Mdm2 at posttranslational level. Meanwhile, GA elevates the expression of p21 regardless of p53 status, and blocks the access of Mdm2 to p21, leading to stabilization of p21 (Rong et al., 2009). Through affecting Mdm2, GA induces cell cycle arrest or apoptosis.

Berberine is a natural product that induces apoptosis in ALL cells possibly by downregulating Mdm2 at a posttranslational level (Zhang et al., 2010). Through interaction with DAXX, Berberine disrupts the formation of Mdm2-DAXX-
HAUSP complex, promoting Mdm2 self-ubiquitination and degradation. The activity of berberine is dependent on the presence of wild-type p53.

\section{FUTURE PERSPECTIVES}

As an essential regulator of the most prevalent tumor suppressor p53 and a variety of other proteins, Mdm2 has attracted a lot of attention. While a great deal has been learnt on how Mdm2 controls p53 expression, activation, and cellular functions, little is known about how Mdm2 regulates other targets. Future studies will focus on investigating the physiologic function of Mdm2-mediated ubiquitination and degradation of other substrates such as insulin receptor substrate-1(IRS-1). One strategy is to use $\mathrm{Mdm}^{-1-} \mathrm{p} 53^{-/-}$ mice to analyze potential developmental defects. Another direction is to study how Mdm2 can integrate external and internal cues to fine-tune the expression of $p 53$ as well as cell proliferation and death. This is particularly important since cells are surrounded by other cells and the extracellular matrix, where signaling molecules as well as nutrients are present and are constantly changing. The Akt-mTOR-S6K1 pathway, which can be activated by metabolic/energy status and regulates the Mdm2-p53 loop, provides such an example. Further unraveling the regulation of Mdm2 will help us to design novel strategies to treat cancer.

\section{ABBREVIATIONS}

ALL, acute myeloid leukemia; AML, acute myeloid leukemia; AP-1, adaptor protein 1; Atm, ataxia telangiectasia mutated; Atr, Atm and Rad3-related; DAXX, death-domain-associated protein; GA, gambogic acid; GPCRs, G-protein-coupled receptors; HAUSP, hepes simplex virus associated ubiquitin-specific protease; HIV-1 vif, human immunodeficiency virus-1 viral infectivity factor; IGF-1, insulin-like growth factor-1; MAPK, mitogen-activated protein kinases; Mdm2, mouse double minute 2; Mls, Mdm2 inhibitors; MYCN, v-myc myelocytomatosis viral related oncoprotein; NES, nuclear export signal; NF-KB, nuclear factor $\mathrm{k}-\mathrm{B}$; NLS, nuclear localization signal; PIKK, phosphatidylinositol 3-kinase related kinase; RASSF1A, Ras-association domain family protein isoform 1A; RFWD3, ring finger and WD repeat domain 3; RMS, rhabdomyosarcoma; RPL26, ribosomal protein L26; RSK, ribosomal S6 kinase; SCYL1-BP1, SCY1-like 1 binding protein 1; ssDNA, singlestranded DNA; TGF- $\beta$, transforming growth factor- $\beta$; HIPK2; homeodomain-interacting protein kinase 2 ; USP2a, ubiquitin-specific protease $2 a$

\section{REFERENCES}

Allred, D.C., Clark, G.M., Elledge, R., Fuqua, S.A., Brown, R.W., Chamness, G.C., Osborne, C.K., and McGuire, W.L. (1993). Association of p53 protein expression with tumor cell proliferation rate and clinical outcome in node-negative breast cancer. J Natl Cancer Inst 85, 200-206.

Araki, S., Eitel, J.A., Batuello, C.N., Bijangi-Vishehsaraei, K., Xie, X. 
J., Danielpour, D., Pollok, K.E., Boothman, D.A., and Mayo, L.D. (2010). TGF-beta1-induced expression of human Mdm2 correlates with late-stage metastatic breast cancer. J Clin Invest 120, 290-302.

Ard, P.G., Chatterjee, C., Kunjibettu, S., Adside, L.R., Gralinski, L.E., and McMahon, S.B. (2002). Transcriptional regulation of the mdm2 oncogene by $\mathrm{p} 53$ requires TRRAP acetyltransferase complexes. Mol Cell Biol 22, 5650-5661.

Argentini, M., Barboule, N., and Wasylyk, B. (2000). The contribution of the RING finger domain of MDM2 to cell cycle progression. Oncogene 19, 3849-3857.

Barak, Y., Gottlieb, E., Juven-Gershon, T., and Oren, M. (1994). Regulation of mdm2 expression by p53: alternative promoters produce transcripts with nonidentical translation potential. Genes Dev 8, 1739-1749.

Blattner, C., Hay, T., Meek, D.W., and Lane, D.P. (2002). Hypophosphorylation of Mdm2 augments p53 stability. Mol Cell Biol 22, 6170-6182.

Blaydes, J.P., and Wynford-Thomas, D. (1998). The proliferation of normal human fibroblasts is dependent upon negative regulation of p53 function by mdm2. Oncogene 16, 3317-3322.

Bond, G.L., Hu, W., Bond, E.E., Robins, H., Lutzker, S.G., Arva, N.C., Bargonetti, J., Bartel, F., Taubert, H., Wuerl, P., et al. (2004). A single nucleotide polymorphism in the MDM2 promoter attenuates the p53 tumor suppressor pathway and accelerates tumor formation in humans. Cell 119, 591-602.

Brady, M., Vlatkovic, N., and Boyd, M.T. (2005). Regulation of p53 and MDM2 activity by MTBP. Mol Cell Biol 25, 545-553.

Buschmann, T., Fuchs, S.Y., Lee, C.G., Pan, Z.Q., and Ronai, Z. (2000). SUMO-1 modification of Mdm2 prevents its selfubiquitination and increases Mdm2 ability to ubiquitinate p53. Cell 101, 753-762.

Buschmann, T., Lerner, D., Lee, C.G., and Ronai, Z. (2001). The Mdm-2 amino terminus is required for Mdm2 binding and SUMO-1 conjugation by the E2 SUMO-1 conjugating enzyme Ubc9. J Biol Chem 276, 40389-40395.

Busuttil, V., Droin, N., McCormick, L., Bernassola, F., Candi, E., Melino, G., and Green, D.R. (2010). NF-\{kappa\}B inhibits T-cell activation-induced, p73-dependent cell death by induction of MDM2. Proc Natl Acad Sci USA 107(42):18061-6.

Candeias, M.M., Malbert-Colas, L., Powell, D.J., Daskalogianni, C., Maslon, M.M., Naski, N., Bourougaa, K., Calvo, F., and Fåhraeus, R. (2008). P53 mRNA controls p53 activity by managing Mdm2 functions. Nat Cell Biol 10, 1098-1105.

Canner, J.A., Sobo, M., Ball, S., Hutzen, B., DeAngelis, S., Willis, W., Studebaker, A.W., Ding, K., Wang, S., Yang, D., et al. (2009). MI63: a novel small-molecule inhibitor targets MDM2 and induces apoptosis in embryonal and alveolar rhabdomyosarcoma cells with wild-type p53. Br J Cancer 101, 774-781.

Chang, Y.C., Lee, Y.S., Tejima, T., Tanaka, K., Omura, S., Heintz, N. H., Mitsui, Y., and Magae, J. (1998). mdm2 and bax, downstream mediators of the p53 response, are degraded by the ubiquitinproteasome pathway. Cell Growth Differ 9, 79-84.

Chen, J., Marechal, V., and Levine, A.J. (1993). Mapping of the p53 and mdm-2 interaction domains. Mol Cell Biol 13, 4107-4114.

Chen, L., Marechal, V., Moreau, J., Levine, A.J., and Chen, J. (1997). Proteolytic cleavage of the $\mathrm{mdm} 2$ oncoprotein during apoptosis. J Biol Chem 272, 22966-22973.
Cheng, Q., and Chen, J. (2010). Mechanism of p53 stabilization by ATM after DNA damage. Cell Cycle 9, 472-478.

Cheng, Q., Chen, L., Li, Z., Lane, W.S., and Chen, J. (2009). ATM activates p53 by regulating MDM2 oligomerization and E3 processivity. EMBO J 28, 3857-3867.

Chi, X.Z., Kim, J., Lee, Y.H., Lee, J.W., Lee, K.S., Wee, H., Kim, W.J., Park, W.Y., Oh, B.C., Stein, G.S., et al. (2009). Runt-related transcription factor RUNX3 is a target of MDM2-mediated ubiquitination. Cancer Res 69, 8111-8119.

de Oca Luna M., R., Wagner, D.S., and Lozano, G. (1995). Rescue of early embryonic lethality in $\mathrm{mdm} 2$-deficient mice by deletion of $\mathrm{p} 53$. Nature 378, 203-206.

Di Stefano, V., Blandino, G., Sacchi, A., Soddu, S., and D'Orazi, G. (2004). HIPK2 neutralizes MDM2 inhibition rescuing p53 transcriptional activity and apoptotic function. Oncogene 23, 5185-5192.

Dias, S.S., Milne, D.M., and Meek, D.W. (2006). c-Abl phosphorylates $\mathrm{Hdm} 2$ at tyrosine 276 in response to DNA damage and regulates interaction with ARF. Oncogene 25, 6666-6671.

Ding, K., Lu, Y., Nikolovska-Coleska, Z., Wang, G., Qiu, S., Shangary, S., Gao, W., Qin, D., Stuckey, J., Krajewski, K., et al. (2006). Structure-based design of spiro-oxindoles as potent, specific small-molecule inhibitors of the MDM2-p53 interaction. J Med Chem 49, 3432-3435.

Dubs-Poterszman, M.C., Tocque, B., and Wasylyk, B. (1995). MDM2 transformation in the absence of p53 and abrogation of the p107 G1 cell-cycle arrest. Oncogene 11, 2445-2449.

Efeyan, A., Ortega-Molina, A., Velasco-Miguel, S., Herranz, D., Vassilev, L.T., and Serrano, M. (2007). Induction of p53-dependent senescence by the MDM2 antagonist nutlin-3a in mouse cells of fibroblast origin. Cancer Res 67, 7350-7357.

Fang, S., Jensen, J.P., Ludwig, R.L., Vousden, K.H., and Weissman, A.M. (2000). Mdm2 is a RING finger-dependent ubiquitin protein ligase for itself and p53. J Biol Chem 275, 8945-8951.

Feng, J., Tamaskovic, R., Yang, Z., Brazil, D.P., Merlo, A., Hess, D., and Hemmings, B.A. (2004). Stabilization of Mdm2 via decreased ubiquitination is mediated by protein kinase B/Akt-dependent phosphorylation. J Biol Chem 279, 35510-35517.

Fu, W., Ma, Q., Chen, L., Li, P., Zhang, M., Ramamoorthy, S., Nawaz, Z., Shimojima, T., Wang, H., Yang, Y., et al. (2009). MDM2 acts downstream of p53 as an E3 ligase to promote FOXO ubiquitination and degradation. J Biol Chem 284, 13987-14000.

Fu, X., Yucer, N., Liu, S., Li, M., Yi, P., Mu, J.J., Yang, T., Chu, J., Jung, S.Y., O'Malley, B.W., et al. (2010). RFWD3-Mdm2 ubiquitin ligase complex positively regulates p53 stability in response to DNA damage. Proc Natl Acad Sci U S A 107, 4579-4584.

Fuchs, S.Y., Adler, V., Buschmann, T., Wu, X., and Ronai, Z. (1998). Mdm2 association with p53 targets its ubiquitination. Oncogene 17, 2543-2547.

Goldberg, Z., Vogt Sionov, R., Berger, M., Zwang, Y., Perets, R., Van Etten, R.A., Oren, M., Taya, Y., and Haupt, Y. (2002). Tyrosine phosphorylation of Mdm2 by c-Abl: implications for $\mathrm{p} 53$ regulation. EMBO J 21, 3715-3727.

Grünbaum, U., Meye, A., Bache, M., Bartel, F., Würl, P., Schmidt, H., Dunst, J., and Taubert, H. (2001). Transfection with mdm2antisense or wtp53 results in radiosensitization and an increased apoptosis of a soft tissue sarcoma cell line. Anticancer Res 21, 2065-2071.

Gu, H., Wang, X., Rao, S., Wang, J., Zhao, J., Ren, F.L., Mu, R., Yang, 
Y., Qi, Q., Liu, W., et al. (2008a). Gambogic acid mediates apoptosis as a p53 inducer through down-regulation of $\mathrm{mdm} 2$ in wild-type p53-expressing cancer cells. Mol Cancer Ther 7, 3298-3305.

Gu, L., Zhu, N., Findley, H.W., and Zhou, M. (2008b). MDM2 antagonist nutlin-3 is a potent inducer of apoptosis in pediatric acute lymphoblastic leukemia cells with wild-type p53 and overexpression of MDM2. Leukemia 22, 730-739.

Halaschek-Wiener, J., Wacheck, V., Kloog, Y., and Jansen, B. (2004). Ras inhibition leads to transcriptional activation of p53 and downregulation of Mdm2: two mechanisms that cooperatively increase p53 function in colon cancer cells. Cell Signal 16, 1319-1327.

Hjerpe, R., Aillet, F., Lopitz-Otsoa, F., Lang, V., Torres-Ramos, M., Farrás, R., Hay, R.T., and Rodríguez, M.S. (2010). Oligomerization conditions Mdm2-mediated efficient p53 polyubiquitylation but not its proteasomal degradation. Int J Biochem Cell Biol 42, 725-735.

Hogan, C., Hutchison, C., Marcar, L., Milne, D., Saville, M., Goodlad, J., Kernohan, N., and Meek, D. (2008). Elevated levels of oncogenic protein kinase Pim-1 induce the p53 pathway in cultured cells and correlate with increased Mdm2 in mantle cell lymphoma. J Biol Chem 283, 18012-18023.

Hollenhorst, P.C., Shah, A.A., Hopkins, C., and Graves, B.J. (2007). Genome-wide analyses reveal properties of redundant and specific promoter occupancy within the ETS gene family. Genes Dev 21, 1882-1894.

Honda, R., and Yasuda, H. (2000). Activity of MDM2, a ubiquitin ligase, toward $\mathrm{p} 53$ or itself is dependent on the RING finger domain of the ligase. Oncogene 19, 1473-1476.

Inoue, T., Geyer, R.K., Howard, D., Yu, Z.K., and Maki, C.G. (2001). MDM2 can promote the ubiquitination, nuclear export, and degradation of p53 in the absence of direct binding. J Biol Chem 276, 45255-45260.

Iwakuma, T., and Lozano, G. (2003). MDM2, an introduction. Mol Cancer Res 1, 993-1000.

Izumi, T., Takaori-Kondo, A., Shirakawa, K., Higashitsuji, H., Itoh, K., lo, K., Matsui, M., Iwai, K., Kondoh, H., Sato, T., et al. (2009). MDM2 is a novel E3 ligase for HIV-1 Vif. Retrovirology $6,1$.

Jones, S., Roe, A., Donehower, L., and Bradley, A. (1995). Rescue of embryonic lethality in Mdm2-deficient mice by absence of p53. Nature 378, 206-208.

Juven, T., Barak, Y., Zauberman, A., George, D.L., and Oren, M. (1993). Wild type p53 can mediate sequence-specific transactivation of an internal promoter within the $\mathrm{mdm} 2$ gene. Oncogene 8 , 3411-3416.

Kastan, M.B., and Bartek, J. (2004). Cell-cycle checkpoints and cancer. Nature 432, 316-323.

Khosravi, R., Maya, R., Gottlieb, T., Oren, M., Shiloh, Y., and Shkedy, D. (1999). Rapid ATM-dependent phosphorylation of MDM2 precedes p53 accumulation in response to DNA damage. Proc Natl Acad Sci U S A 96, 14973-14977.

Kim, D., Song, J., and Jin, E.J. (2010). MicroRNA-221 regulates chondrogenic differentiation through promoting proteosomal degradation of slug by targeting Mdm2. J Biol Chem 285, 26900-26907.

Kojima, K., Konopleva, M., Samudio, I.J., Shikami, M., CabreiraHansen, M., McQueen, T., Ruvolo, V., Tsao, T., Zeng, Z., Vassilev, L.T., et al. (2005). MDM2 antagonists induce p53-dependent apoptosis in AML: implications for leukemia therapy. Blood 106,
3150-3159.

Kondo, S., Barnett, G.H., Hara, H., Morimura, T., and Takeuchi, J. (1995). MDM2 protein confers the resistance of a human glioblastoma cell line to cisplatin-induced apoptosis. Oncogene 10, 2001-2006.

Kussie, P.H., Gorina, S., Marechal, V., Elenbaas, B., Moreau, J., Levine, A.J., and Pavletich, N.P. (1996). Structure of the MDM2 oncoprotein bound to the p53 tumor suppressor transactivation domain. Science 274, 948-953.

Lai, K.P., Leong, W.F., Chau, J.F., Jia, D., Zeng, L., Liu, H., He, L., Hao, A., Zhang, H., Meek, D., et al. (2010). S6K1 is a multifaceted regulator of $\mathrm{Mdm} 2$ that connects nutrient status and DNA damage response. EMBO J 29, 2994-3006.

Lee, M.H., Lee, S.W., Lee, E.J., Choi, S.J., Chung, S.S., Lee, J.I., Cho, J.M., Seol, J.H., Baek, S.H., Kim, K.I., et al. (2006). SUMOspecific protease SUSP4 positively regulates p53 by promoting Mdm2 self-ubiquitination. Nat Cell Biol 8, 1424-1431.

$\mathrm{Li}, \mathrm{B}$. (2005). c-Abl in oxidative stress, aging and cancer. Cell Cycle 4 , 246-248.

Li, M., Brooks, C.L., Kon, N., and Gu, W. (2004). A dynamic role of HAUSP in the p53-Mdm2 pathway. Mol Cell 13, 879-886.

Li, M., Brooks, C.L., Wu-Baer, F., Chen, D., Baer, R., and Gu, W. (2003). Mono- versus polyubiquitination: differential control of p53 fate by Mdm2. Science 302, 1972-1975.

Lu, X., Ma, O., Nguyen, T.A., Jones, S.N., Oren, M., and Donehower, L.A. (2007). The Wip1 Phosphatase acts as a gatekeeper in the p53-Mdm2 autoregulatory loop. Cancer Cell 12, 342-354.

Lu, X., Nguyen, T.A., Zhang, X., and Donehower, L.A. (2008). The Wip1 phosphatase and Mdm2: cracking the "Wip" on p53 stability. Cell Cycle 7, 164-168.

Maguire, M., Nield, P.C., Devling, T., Jenkins, R.E., Park, B.K., Polański, R., Vlatković, N., and Boyd, M.T. (2008). MDM2 regulates dihydrofolate reductase activity through monoubiquitination. Cancer Res 68, 3232-3242.

Maki, C.G. (1999). Oligomerization is required for p53 to be efficiently ubiquitinated by MDM2. J Biol Chem 274, 16531-16535.

Manfredi, J.J. (2010). The Mdm2-p53 relationship evolves: Mdm2 swings both ways as an oncogene and a tumor suppressor. Genes Dev 24, 1580-1589.

Maya, R., Balass, M., Kim, S.T., Shkedy, D., Leal, J.F., Shifman, O., Moas, M., Buschmann, T., Ronai, Z., Shiloh, Y., et al. (2001). ATMdependent phosphorylation of Mdm2 on serine 395: role in p53 activation by DNA damage. Genes Dev 15, 1067-1077.

Mayo, L.D., and Donner, D.B. (2001). A phosphatidylinositol 3-kinase/ Akt pathway promotes translocation of Mdm2 from the cytoplasm to the nucleus. Proc Natl Acad Sci U S A 98, 11598-11603.

Meek, D.W., and Hupp, T.R. (2010). The regulation of MDM2 by multisite phosphorylation-opportunities for molecular-based intervention to target tumours? Semin Cancer Biol 20, 19-28.

Meng, L.H., Kohlhagen, G., Liao, Z.Y., Antony, S., Sausville, E., and Pommier, Y. (2005). DNA-protein cross-links and replicationdependent histone H2AX phosphorylation induced by aminoflavone (NSC 686288), a novel anticancer agent active against human breast cancer cells. Cancer Res 65, 5337-5343.

Meulmeester, E., Pereg, Y., Shiloh, Y., and Jochemsen, A.G. (2005). ATM-mediated phosphorylations inhibit Mdmx/Mdm2 stabilization by HAUSP in favor of p53 activation. Cell Cycle 4, 1166-1170.

Milne, D., Kampanis, P., Nicol, S., Dias, S., Campbell, D.G., Fuller- 
Pace, F., and Meek, D. (2004). A novel site of AKT-mediated phosphorylation in the human MDM2 onco-protein. FEBS Lett 577, 270-276.

Mo, P., Wang, H., Lu, H., Boyd, D.D., and Yan, C. (2010). MDM2 mediates ubiquitination and degradation of activating transcription factor 3. J Biol Chem 285, 26908-26915.

Moll, U.M., and Petrenko, O. (2003). The MDM2-p53 interaction. Mol Cancer Res 1, 1001-1008.

Momand, J., Zambetti, G.P., Olson, D.C., George, D., and Levine, A.J. (1992). The mdm-2 oncogene product forms a complex with the p53 protein and inhibits p53-mediated transactivation. Cell 69, 1237-1245.

Naski, N., Gajjar, M., Bourougaa, K., Malbert-Colas, L., Fåhraeus, R., and Candeias, M.M. (2009). The p53 mRNA-Mdm2 interaction. Cell Cycle 8, 31-34.

Ofir-Rosenfeld, Y., Boggs, K., Michael, D., Kastan, M.B., and Oren, M. (2008). Mdm2 regulates p53 mRNA translation through inhibitory interactions with ribosomal protein L26. Mol Cell 32, 180-189.

Pettersson, S., Kelleher, M., Pion, E., Wallace, M., and Ball, K.L. (2009). Role of Mdm2 acid domain interactions in recognition and ubiquitination of the transcription factor IRF-2. Biochem J 418, 575-585.

Phelps, M., Darley, M., Primrose, J.N., and Blaydes, J.P. (2003). p53independent activation of the hdm2-P2 promoter through multiple transcription factor response elements results in elevated hdm2 expression in estrogen receptor alpha-positive breast cancer cells. Cancer Res 63, 2616-2623.

Pikkarainen, S., Kennedy, R.A., Marshall, A.K., Tham, L., Lay, K., Kriz, T.A., Handa, B.S., Clerk, A., and Sugden, P.H. (2009). Regulation of expression of the rat orthologue of mouse double minute 2 (MDM2) by $\mathrm{H}(2) \mathrm{O}(2)$-induced oxidative stress in neonatal rat cardiac myocytes. J Biol Chem 284, 27195-27210.

Pochampally, R., Fodera, B., Chen, L., Lu, W., and Chen, J. (1999). Activation of an MDM2-specific caspase by p53 in the absence of apoptosis. J Biol Chem 274, 15271-15277.

Poyurovsky, M.V., Katz, C., Laptenko, O., Beckerman, R., Lokshin, M., Ahn, J., Byeon, I.J., Gabizon, R., Mattia, M., Zupnick, A., et al. (2010). The $\mathrm{C}$ terminus of $\mathrm{p} 53$ binds the $\mathrm{N}$-terminal domain of MDM2. Nat Struct Mol Biol 17, 982-989.

Poyurovsky, M.V., Priest, C., Kentsis, A., Borden, K.L., Pan, Z.Q., Pavletich, N., and Prives, C. (2007). The Mdm2 RING domain Cterminus is required for supramolecular assembly and ubiquitin ligase activity. EMBO J 26, 90-101.

Qi, J.S., Yuan, Y., Desai-Yajnik, V., and Samuels, H.H. (1999). Regulation of the mdm2 oncogene by thyroid hormone receptor. Mol Cell Biol 19, 864-872.

Ray, R.M., Bhattacharya, S., and Johnson, L.R. (2010). Mdm2 inhibition induces apoptosis in p53 deficient human colon cancer cells by activating p73- and E2F1-mediated expression of PUMA and Siva-1. Apoptosis 2010 Sep 2. [Epub ahead of print] DOI: 10.1007/s10495-010-0538-0

Ries, S., Biederer, C., Woods, D., Shifman, O., Shirasawa, S., Sasazuki, T., McMahon, M., Oren, M., and McCormick, F. (2000). Opposing effects of Ras on p53: transcriptional activation of $\mathrm{mdm} 2$ and induction of p19ARF. Cell 103, 321-330.

Rong, J.J., Hu, R., Qi, Q., Gu, H.Y., Zhao, Q., Wang, J., Mu, R., You, Q.D., and Guo, Q.L. (2009). Gambogic acid down-regulates MDM2 oncogene and induces p21(Waf1/CIP1) expression independent of p53. Cancer Lett 284, 102-112.

Samudio, I.J., Duvvuri, S., Clise-Dwyer, K., Watt, J.C., Mak, D., Kantarjian, H., Yang, D., Ruvolo, V., and Borthakur, G. (2010). Activation of p53 signaling by Ml-63 induces apoptosis in acute myeloid leukemia cells. Leuk Lymphoma 51, 911-919.

Sashida, G., Liu, Y., Elf, S., Miyata, Y., Ohyashiki, K., Izumi, M., Menendez, S., and Nimer, S.D. (2009). ELF4/MEF activates MDM2 expression and blocks oncogene-induced $\mathrm{p} 16$ activation to promote transformation. Mol Cell Biol 29, 3687-3699.

Sato, N., Mizumoto, K., Maehara, N., Kusumoto, M., Nishio, S., Urashima, T., Ogawa, T., and Tanaka, M. (2000). Enhancement of drug-induced apoptosis by antisense oligodeoxynucleotides targeted against Mdm2 and p21WAF1/CIP1. Anticancer Res 20, 837-842.

Shangary, S., Qin, D., McEachern, D., Liu, M., Miller, R.S., Qiu, S., Nikolovska-Coleska, Z., Ding, K., Wang, G., Chen, J., et al. (2008). Temporal activation of p53 by a specific MDM2 inhibitor is selectively toxic to tumors and leads to complete tumor growth inhibition. Proc Natl Acad Sci U S A 105, 3933-3938.

Sheikh, M.S., Shao, Z.M., Hussain, A., and Fontana, J.A. (1993). The p53-binding protein MDM2 gene is differentially expressed in human breast carcinoma. Cancer Res 53, 3226-3228.

Shinozaki, T., Nota, A., Taya, Y., and Okamoto, K. (2003). Functional role of Mdm2 phosphorylation by ATR in attenuation of p53 nuclear export. Oncogene 22, 8870-8880.

Slack, A., Chen, Z., Tonelli, R., Pule, M., Hunt, L., Pession, A., and Shohet, J.M. (2005). The p53 regulatory gene MDM2 is a direct transcriptional target of MYCN in neuroblastoma. Proc Natl Acad Sci U S A 102, 731-736.

Song, M.S., Song, S.J., Kim, S.Y., Oh, H.J., and Lim, D.S. (2008). The tumour suppressor RASSF1A promotes MDM2 self-ubiquitination by disrupting the MDM2-DAXX-HAUSP complex. EMBO J 27, 1863-1874.

Stad, R., Little, N.A., Xirodimas, D.P., Frenk, R., van der Eb, A.J., Lane, D.P., Saville, M.K., and Jochemsen, A.G. (2001). Mdmx stabilizes p53 and Mdm2 via two distinct mechanisms. EMBO Rep 2, 1029-1034.

Stevenson, L.F., Sparks, A., Allende-Vega, N., Xirodimas, D.P., Lane, D.P., and Saville, M.K. (2007). The deubiquitinating enzyme USP2a regulates the p53 pathway by targeting Mdm2. EMBO J 26, 976-986.

Sun, P., Dong, P., Dai, K., Hannon, G.J., and Beach, D. (1998). p53independent role of MDM2 in TGF-beta1 resistance. Science 282, 2270-2272.

Tang, J., Qu, L.K., Zhang, J., Wang, W., Michaelson, J.S., Degenhardt, Y.Y., El-Deiry, W.S., and Yang, X. (2006). Critical role for Daxx in regulating Mdm2. Nat Cell Biol 8, 855-862.

Tortora, G., Caputo, R., Damiano, V., Bianco, R., Chen, J., Agrawal, S., Bianco, A.R., and Ciardiello, F. (2000). A novel MDM2 antisense oligonucleotide has anti-tumor activity and potentiates cytotoxic drugs acting by different mechanisms in human colon cancer. Int J Cancer 88, 804-809.

Truong, A.H., Cervi, D., Lee, J., and Ben-David, Y. (2005). Direct transcriptional regulation of MDM2 by Fli-1. Oncogene 24, 962-969.

Tyner, S.D., Venkatachalam, S., Choi, J., Jones, S., Ghebranious, N., Igelmann, H., Lu, X., Soron, G., Cooper, B., Brayton, C., et al. (2002). p53 mutant mice that display early ageing-associated 
phenotypes. Nature 415, 45-53.

Vassilev, L.T., Vu, B.T., Graves, B., Carvajal, D., Podlaski, F., Filipovic, Z., Kong, N., Kammlott, U., Lukacs, C., Klein, C., et al. (2004). In vivo activation of the p53 pathway by small-molecule antagonists of MDM2. Science 303, 844-848.

Wang, P., Gao, H., Ni, Y., Wang, B., Wu, Y., Ji, L., Qin, L., Ma, L., and Pei, G. (2003). Beta-arrestin 2 functions as a G-protein-coupled receptor-activated regulator of oncoprotein Mdm2. J Biol Chem 278, 6363-6370.

Waning, D.L., Lehman, J.A., Batuello, C.N., and Mayo, L.D. (2010). Controlling the Mdm2-Mdmx-p53 Circuit. Pharmaceuticals (Basel) 3, 1576-1593.

Wood, N.T., Meek, D.W., and Mackintosh, C. (2009). 14-3-3 Binding to Pim-phosphorylated Ser166 and Ser186 of human Mdm2Potential interplay with the PKB/Akt pathway and p14(ARF). FEBS Lett 583, 615-620.

Wu, X., Bayle, J.H., Olson, D., and Levine, A.J. (1993). The p53mdm-2 autoregulatory feedback loop. Genes Dev 7, 1126-1132.

Yan, J., Zhang, D., Di, Y., Shi, H., Rao, H., and Huo, K. (2010). A newly identified Pirh2 substrate SCYL1-BP1 can bind to MDM2 and accelerate MDM2 self-ubiquitination. FEBS Lett 584, 3275-3278.
Yang, H.Y., Wen, Y.Y., Lin, Y.I., Pham, L., Su, C.H., Yang, H., Chen, J., and Lee, M.H. (2007). Roles for negative cell regulator 14-33sigma in control of MDM2 activities. Oncogene 26, 7355-7362.

Zhang, X., Gu, L., Li, J., Shah, N., He, J., Yang, L., Hu, Q., and Zhou, M. (2010). Degradation of MDM2 by the interaction between berberine and DAXX leads to potent apoptosis in MDM2overexpressing cancer cells. [Epub ahead of print] [PMID: 20935220] Cancer Res 2010, 23.

Zhang, X.C., Chen, J., Su, C.H., Yang, H.Y., and Lee, M.H. (2008). Roles for CSN5 in control of p53/MDM2 activities. J Cell Biochem 103, 1219-1230.

Zheng, T., Wang, J., Chen, X., Meng, X., Song, X., Lu, Z., Jiang, H., and Liu, L. (2010). Disruption of p73-MDM2 binding synergizes with gemcitabine to induce apoptosis in HuCCT1 cholangiocarcinoma cell line with p53 mutation. Tumour Biol 31, 287-295.

Zhou, B.B., and Elledge, S.J. (2000). The DNA damage response: putting checkpoints in perspective. Nature 408, 433-439.

Zhou, B.P., and Hung, M.C. (2002). Novel targets of Akt, p21(Cipl/ WAF1), and MDM2. Semin Oncol 29, 62-70.

Zhou, B.P., Liao, Y., Xia, W., Zou, Y., Spohn, B., and Hung, M.C. (2001). HER-2/neu induces p53 ubiquitination via Akt-mediated MDM2 phosphorylation. Nat Cell Biol 3, 973-982. 